\title{
Correction to: Comparison between 5-aminolevulinic acid photodynamic diagnosis and narrow-band imaging for bladder cancer detection
}

Hiroki Hagimoto ${ }^{*}$, Noriyuki Makita, Yuta Mine, Hidetoshi Kokubun, Shiori Murata, Yohei Abe, Masashi Kubota, Naofumi Tsutsumi, Toshinari Yamasaki and Mutsushi Kawakita

\section{Correction to: BMC Urol 2021 21(1):180}

https://doi.org/10.1186/s12894-021-00946-w

Following publication of the original article [1], it was noted that due to a typesetting error the Fig. 1 was incorrect. The correct figure is given below.

Second, the authors would like to correct the reference number in the second paragraph under the heading Discussion section.
The sentence should read:

Although observation at 2-4 $\mathrm{h}$ after 5-ALA oral administration is recommended, the time of 5-ALA exposure to light may be less important, as it has been shown that no significant difference exists between exposure times of $2-3 \mathrm{~h}$ and $4 \mathrm{~h}$ or more [13].

The original article [1] has been corrected.

Published online: 17 February 2022

\section{Reference}

1. Hagimoto et al. Comparison between 5-aminolevulinic acid photodynamic diagnosis and narrow-band imaging for bladder cancer detection. BMC Urol. 2021;21(1):180. https://doi.org/10.1186/s12894-021-00946-w

\section{Publisher's Note}

Springer Nature remains neutral with regard to jurisdictional claims in published maps and institutional affiliations. 


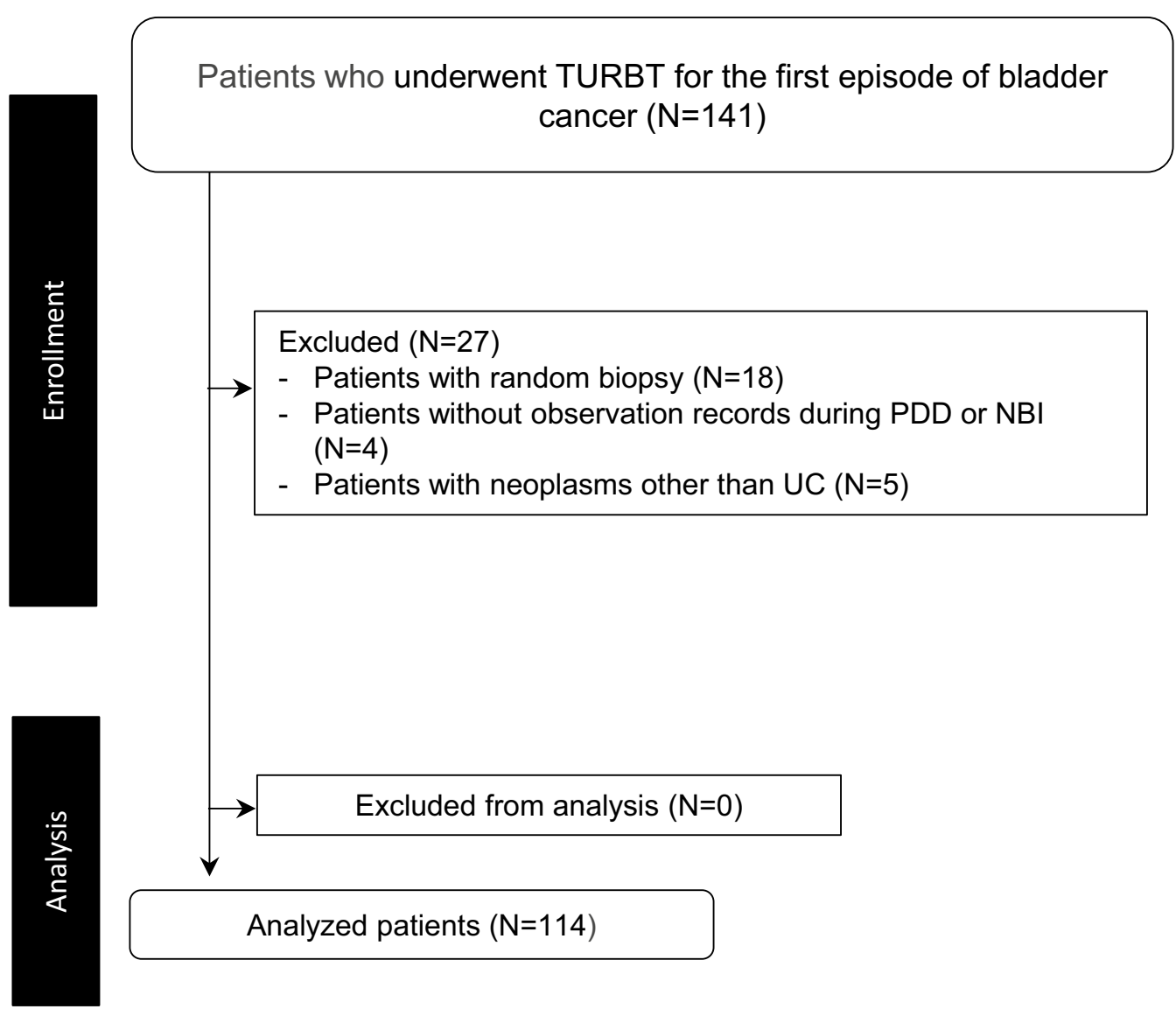

Fig. 1 Flow diagram of patient enrolment 